\title{
As POLÍTICAS CULTURAIS COMO UM CAMPO DE GOVERNO: ARTISTAS EMPREENDEDORES DE SI
}

\author{
Sharine Machado C. Melo \\ Fundação Nacional de Artes, Brasil
}

\begin{abstract}
Resumo
Este artigo apresenta alguns aspectos da obra do pesquisador inglês Tony Bennett (1988, $1998,2008,2011)$ sobre as políticas culturais e os circuitos artísticos. O autor adota o conceito de governamentalidade, proposto por Foucault (2016), e sugere que o encontro da estética pós-kantiana com o pensamento liberal, no final do século XVIII, criou condições para que as artes e a cultura passassem a ser vistas como um campo de governo. Essa tendência é visível no desenvolvimento das políticas culturais, especialmente a partir de meados do século XX e, mais recentemente, na difusão do conceito de economia criativa. Em seguida, a proposta é avançar sobre o pensamento de Foucault (2008), especialmente sobre as noções de empreendedorismo e capital humano. A hipótese é que um dos fatores que faz dos circuitos da arte um foco de interesse na sociedade atual é a maneira como os artistas investem a própria vida na criação de suas obras. Com isso, multiplicam-se grupos de interesse, que lutam por melhores condições de trabalho e políticas públicas. Por outro lado, corre-se o risco de que as redes se fechem em seus próprios circuitos, fragmentando o campo cultural. O desafio é fazer com que as artes e a cultura se transformem, de fato, em um bem comum, que faça parte do cotidiano da população.
\end{abstract}

\section{PaLAVRas-Chave}

governamentalidade; empreendedorismo; arte; cultura; políticas culturais

\section{Cultural policy as a governmental FIELD: ENTREPRENEUR ARTISTS}

\begin{abstract}
This article presents some aspects of the work of the British researcher Tony Bennett $(1988,1998,2008,2011)$ about cultural policy and artistic field. The author adopts Foucault's (2016) concept on governmentality and suggests the encounter between post-Kantian aesthetics and liberal thought at the end of the eighteenth century allowed for the arts and cultures to be understood as a governmental field. This trend can be seen in the development of cultural policies, particularly those starting from the middle of the twentieth century, and, more recently, in the spread of the concept of creative economy. We further elaborate on Foucault's thought, especially on entrepreneurship and human capital. The hypothesis is that one of the factors that transforms art circuits into a matter of concern in contemporary society is the manner how artists invest their own life into artistic production. Interest groups are multiplied and struggle for better work conditions and public policies. On the other hand, networks run the risk of limiting themselves to their own circuits, thus fragmenting the cultural field. The challenge is to turn art and culture into a common good, which is part of the population's daily life.
\end{abstract}




\section{INTRODUÇÃo}

Acontecimentos recentes, como a extinção e a recriação do Ministério da Cultura durante o governo de Michel Temer e mudanças na Lei de Incentivo (Lei n 8.313/1991), têm colocado a cultura e as artes em pauta nos meios de comunicação brasileiros, embora as notícias nem sempre sejam positivas: cortes de verba e falta de preservação do patrimônio são alguns dos problemas. Ao mesmo tempo, termos como "economia criativa" ou "economia da cultura" são repetidos por gestores, pesquisadores e economistas. Para além das ações político-partidárias, o que se percebe (mesmo quando há pessimismo e certo tom nostálgico) é que, de alguma maneira, as artes e a cultura chamam a atenção nas sociedades contemporâneas.

No lançamento dos dois primeiros volumes do Atlas Econômico da Cultura Brasileira, em abril de 2017, o então Ministro da Cultura Roberto Freire ressaltou que, de acordo com estudo publicado em 2010 pela UNCTAD (Conferência das Nações Unidas sobre Comércio e Desenvolvimento), a cultura é responsável por $4 \%$ do PIB (Produto Interno Bruto) brasileiro (Bocchini, 2017). Além da questão econômica, na primeira década dos anos 2000, a proliferação de editais e prêmios para as linguagens artísticas também contribuiu para que o trabalho de artistas e coletivos se multiplicasse no país, especialmente em grandes cidades, como São Paulo e Rio de Janeiro. Por esses e outros motivos, parece um consenso afirmar que o incentivo às artes e à cultura é importante - e, de fato, ele é fundamental nos tempos atuais.

Mas, segundo Foucault, nem tudo pode ser pensado em todas as épocas. As artes, como ainda as entendemos, são uma invenção moderna, de pouco mais de dois séculos. Para o historiador Larry Shiner (2001), elas emergem do encontro de instituições (museus, galerias, bibliotecas, teatros, academias), ideias (como as diversas correntes estéticas) e relações de poder. Foi somente no final do século XVIII, com o declínio das monarquias absolutistas e o desenvolvimento do mercado, que esse conjunto de práticas e enunciados se afirmou como um campo autônomo frente à economia e à política - ou, mais precisamente, como um espaço de disputas, permeado por ambivalentes relações de força e poder, sempre em busca de uma coerência interna ou de algo que o diferencie de outros aspectos da sociedade.

Como descrito por Bourdieu (1998), foi a luta diária de uma geração que contribuiu para que as linguagens artísticas e seus circuitos se tornassem autorreferentes no século XIX. Porém, são muitos os circuitos da arte, como são muitas as diferenças e as conexões, as divergências e justaposições entre cultura, política e economia: das propostas de caráter predominantemente comercial aos protestos políticos e à negação do mercado pelas correntes experimentais. Mais do que circuitos, formam-se redes de artistas, investidores, críticos e empresários, que se interessam por determinados temas ou linguagens, adotam estilos de vida semelhantes e compartilham códigos de conduta. 
Também são inúmeras as abordagens possíveis sobre esse campo. O pesquisador inglês Tony Bennett $(1998,2011)$ optou por olhar para a tradição estética que, a partir da experiência europeia, estabeleceu-se em grande parte do ocidente desde o final do século XVIII. O autor aproximou-se do conceito de governamentalidade, proposto por Foucault (2016), para investigar como a arte e a cultura se transformaram não somente em um foco de interesses, mas principalmente em algo a ser gerido. Se o que hoje se entende por arte foi construído, não sem conflitos, pelo esforço de artistas e outros profissionais, a necessidade de traçar políticas públicas para a cultura' também não é evidente: ela emerge de condições históricas específicas, como o crescimento das indústrias culturais, mas também da liberdade humana de agir. Por isso, é necessário o empenho de governos, iniciativas privadas e da sociedade em geral.

A proposta deste artigo é apresentar alguns aspectos da obra de Bennett. O autor remete constantemente para a Inglaterra, não por ser sua terra natal, mas para dialogar com os Estudos Culturais e porque o país foi um dos berços do liberalismo econômico. Bennett (2008) acredita que foi o encontro entre o pensamento liberal e o regime estético que, antes mesmo do crescimento das indústrias culturais, levou a gestão das artes e da cultura a ser pensada nas terras britânicas, ainda de modo utilitarista. Após apresentar alguns tópicos da obra do autor, a ideia é avançar sobre os conceitos de empreendedorismo e capital humano, também estudados por Foucault (2008). A hipótese é que, atualmente, a maneira como os artistas investem a própria vida na luta diária pela criação de suas obras é um dos fatores que iluminam os circuitos da arte e fazem deles um foco de interesses.

\section{FOUCAULT E OS ESTUDOS SOBRE A CULTURA}

Bennett não foi o primeiro pesquisador de sua área a dialogar com Foucault. Nos anos 1960, os fundadores dos Estudos Culturais, entre eles Raymond Williams (1967) e Stuart Hall (1980), procuravam diferenciar dois conceitos de cultura: o primeiro, relacionado ao campo autônomo das Belas Artes, remete a certo "ideal de perfeição"; já o segundo, adotado pelos pesquisadores, é mais amplo e refere-se ao "ato de atribuir e de receber sentidos". Com isso, os autores sugeriam que, após um período dominado pela tradição estética, a cultura se tornasse ordinária, cotidiana, e propunham que esse termo tão difícil de definir fosse repensado em suas relações de poder. Para eles, a cultura é um espaço complexo, em que diferentes influências se combinam e entram em conflito. A linha de pesquisa cresceu e fragmentou-se, mas até hoje predominam algumas questões comuns em torno das representações, da identidade, da subjetividade e da autoridade dos enunciados que se destacam nos múltiplos grupos sociais: "quem está falando?" (Hesmondhalgh, 2013).

O interesse pelo presente e as relações entre poder e saber, essenciais a Foucault, são visíveis nessas formulações. Contudo, eram distintas as referências teóricas. Enquanto Williams (1967) e seus colegas partiam de motivações marxistas, como o desejo

\footnotetext{
'Conjunto de ações de governo que incidem sobre as práticas artísticas e culturais da população.
} 
de dar voz às classes trabalhadoras, revelando a multiplicidade de suas manifestações artísticas e culturais, o pensador francês se esforçava para mostrar que as relações de poder são sempre bilaterais. O poder - seja ele político, religioso ou social - não é localizado, não está somente no Estado, no Capital ou em uma classe dominante. Ele se espalha pela sociedade. Esse foi o principal ponto de divergência entre as propostas: Foucault foi criticado por "não perceber como as relações econômicas do capitalismo constituiriam um princípio unificado de formação social". Ou seja, o filósofo era repreendido na Inglaterra justamente em razão daquilo que sua obra tinha de singular: sua concepção de microfísica do poder não chegava a formar uma base para uma luta mais ampla da sociedade, com "potencial revolucionário" (Bennett, 1998, p. 63).

O conceito que prevaleceu entre os pesquisadores dos Estudos Culturais foi, então, o de hegemonia, proposto pelo filósofo marxista Antonio Gramsci. Se, para Foucault, o poder é disperso, para Gramsci (citado em Bennett, 1998), ele tem uma origem unificada. Em resumo, sua tese é a de que as classes populares aspiram suporte e participação ativa nos projetos das classes dominantes. Há, portanto, a formação de um consenso, em que estão em jogo forças hegemônicas e contra-hegemônicas. O papel dos pesquisadores seria o de analisar essas forças de modo a poder lutar contra os processos de dominação.

Bennett (1998) nos lembra que, em sua leitura da tradição romântica, Williams não criticava somente o elitismo da definição de cultura, mas também as dificuldades práticas: como propor modos de resistência a partir de um conceito totalizante? Ele procurava, ainda, distanciar-se dos intelectuais que diziam que o engajamento com as formas existentes de políticas públicas não era necessário, afastando-se da crítica cultural abstrata e transcendente. $\mathrm{O}$ autor chegou a colaborar com instituições culturais após a Segunda Guerra Mundial e a reconhecer a importância de Keynes, o arquiteto do Arts Council, por seu "espírito aberto". Contudo, Bennett (1998) também afirma que, apesar do engajamento de Williams, por muito tempo, questões sobre políticas públicas estiveram praticamente ausentes dos debates propostos pelos Estudos Culturais. Ao adotar o conceito de hegemonia, que perpassa a sociedade como um todo, muitos pesquisadores deixavam de olhar para as questões práticas. Além disso, ao se opor à noção romântica de cultura, Williams e seus colegas deixaram de perceber que, apesar da relevância de seu trabalho, eles não eram os únicos a se preocupar com a diversidade. Afinal, o desenvolvimento desse campo de pesquisas coincide com a abrangência da cultura popular, de massa ou cotidiana também por parte dos órgãos governamentais.

Realmente, após a Segunda Guerra Mundial, com a emancipação de colônias europeias na África e na Ásia e o crescimento dos movimentos migratórios, os modos de vida dos diversos grupos sociais passaram a ser um foco de atenção dos governos, que buscavam estratégias para absorver essa população na sociedade. Bennett cita como exemplo métodos de ensino em escolas públicas inglesas que, pela primeira vez, lidavam com alunos que não tinham acesso aos padrões culturais europeus. Professores, psicólogos e pedagogos passavam a valorizar os hábitos e os artefatos culturais dos lugares de origem dos alunos, como uma maneira de se aproximarem das crianças e 
adolescentes. Além disso, os meios de comunicação se desenvolviam e as indústrias culturais cresciam, principalmente nos Estados Unidos, que passavam a exportar filmes e músicas para todo o mundo.

Governos de outros países também voltavam o olhar para as artes nesse mesmo período. O principal exemplo é a França, que criou, em 1959, o Ministère d'État chargé des Affaires Culturelles, conhecido como o primeiro Ministério da Cultura do mundo, na acepção atual do termo. As ações para fomento aos artistas, preservação do patrimônio e democratização cultural foram os pilares do ministério durante a gestão de André Malraux (Poirrier, 2012). No entanto, a diversidade cultural e os meios de comunicação de massa rapidamente entraram em pauta. Em um panfleto escrito em 1968, Jean Dubuffet opunha a noção de diversidade à centralização exercida pelo Estado na área cultural: “nesse campo, é nocivo tudo o que tende para a hierarquização, para a seleção, para a concentração, porque o resultado é esterilizar o vasto, o incontável e abundante terreno fértil das multidões" (Dubuffet, 2012, p. 69).

Essas questões tinham ressonâncias internacionais. Apesar do ânimo libertário dos eventos de maio de 1968, nos anos seguintes, intensificaram-se os debates sobre o papel do Estado no campo cultural. Em 1970, foi realizada, em Veneza, a "Conferência intergovernamental sobre os aspectos institucionais, administrativos e financeiros das políticas culturais". Entre as recomendações do relatório final, estavam: a criação de políticas de estado para a cultura e o fortalecimento das identidades nacionais, principalmente nas antigas colônias, situadas na Ásia e na África, que teriam hábitos e costumes tradicionais ameaçados pelas indústrias culturais. O Brasil, ainda em meio à ditadura militar, chegou a apresentar um projeto na conferência, o que viria a ser o Plano de Ação Cultural (PAC), lançado em 1973, para financiamento de atividades nas áreas de música, folclore, circo, teatro e cinema. Em 1975, o governo brasileiro criou a Fundação Nacional de Artes (Funarte). Ainda sob regime militar, pela primeira vez uma política cultural estruturada, de caráter nacional, era pensada no país.

Em 1981, uma nova mudança veio da França: o ministério da cultura passou a se chamar Ministère de la Culture et de la Communication e teve sua missão modificada: a criatividade individual tomava o lugar da democratização da arte e o respeito pelas culturas regionais e internacionais era enfatizado (Poirrier, 2012). Seguindo essa direção, nos anos 1980 houve uma ênfase crescente no multiculturalismo, e o então ministro da cultura francês, Jack Lang, tornou-se internacionalmente conhecido por estender as políticas a gêneros que antes eram "excluídos", como o rock e o hip-hop. No Brasil, o Ministério da Cultura foi transformado em uma pasta autônoma em 1985, já com a proposta mais ampla de fomentar a criatividade. Em seu discurso de posse, o economista Celso Furtado afirma:

vivemos numa civilização em rápida transformação. Numa época de revolução nas tecnologias de comunicação. A cultura não é apenas o acervo que recebemos do passado. Por mais importante que seja a defesa da herança cultural, não podemos desconhecer que a essência do homem como 
criador de cultura reside em sua criatividade, em poder romper com o passado ao mesmo tempo que dele se alimenta (...). Criar condições para que a criatividade seja exercida em sua plenitude - eis a essência do que chamamos de democracia. (Furtado, 2012, pp. 52-53)

A tendência iria se fortalecer, principalmente em países anglo-saxões, a partir da década de 1990: a cultura, baseada agora no conceito de criatividade, passava a ser vista como um dos motores da economia. Em 1994, a Austrália foi declarada Nação Criativa e, em 1997, Tony Blair formou uma equipe para mapear as indústrias criativas do Reino Unido, ao mesmo tempo em que aumentava o subsídio para as artes. Não demorou para que a ideia se espalhasse pelo mundo. Em 2005, o governo brasileiro assinou a "Convenção sobre a proteção e promoção da diversidade das expressões culturais", promovida pela Unesco. Nesse documento, a cultura assumia o papel de "elemento estratégico" para o "desenvolvimento sustentável" e se tornava "fonte de riquezas materiais e imateriais", capaz de contribuir para a "erradicação da pobreza", a proteção de saberes "tradicionais", a melhoria da "condição das mulheres", entre outros temas. Os objetivos seriam alcançados mediante a "livre circulação de ideias", as "trocas constantes" e a "interação entre as culturas". A globalização era citada como uma oportunidade, mas também como risco de "desequilíbrios entre países ricos e pobres". Nesse contexto, alguns pesquisadores (pertencentes a uma geração que Hesmondhalgh, 2013, chama de quase-foucaultiana, por se desviar de seus propósitos iniciais) voltou a atenção para novas formas de políticas públicas, que tinham o objetivo de expandir o papel econômico das indústrias culturais, agora chamadas de indústrias criativas. Em um misto de otimismo tecnológico e pós-modernismo, autores como John Hartley (citado em Hesmondhalgh, 2013) acabavam se debruçando cada vez mais sobre aspectos práticos e administrativos e afastando-se da crítica às relações de poder.

Esse cenário de explosão criativa acabou gerando repercussões negativas. Alguns autores argumentam que questões estéticas são deixadas em segundo plano quando o que está em jogo é a inovação, em termos mercadológicos. Realmente, o conceito de economia criativa foi construído sobre o aumento do valor da propriedade intelectual e o crescimento de atividades como design, produção de software, propaganda, artes performáticas, editoração e mercado de artes. Mas Thomas Osborne (2003, p. 508) ressalta que, embora pareça ser meramente ideológico, uma resposta às necessidades do capitalismo, dizer que o constante apelo pela criatividade simplesmente responde a necessidades estruturais seria "ignorar o fato de que a explosão criativa também é um produto da ação humana", das "maquinações de especialistas" e dos "trabalhadores do intelecto". A criatividade não é somente algo que se espera encontrar. Psicólogos, gestores e profissionais de recursos humanos, entre outros, não cessam de buscar condições para que ela seja produzida. Isso faz da criatividade um problema não apenas de ideologia, mas principalmente de governamentalidade, para usar o termo cunhado por Foucault (2016). Ora, entre as principais questões dos movimentos artísticos modernos e contemporâneos, estão justamente a quebra de paradigmas, a originalidade e a 
criação. Por isso, as artes certamente estão inseridas nesse modo de gerir a vida que, de alguma forma, já estava presente antes mesmo de serem fundados os Estudos Culturais e se intensificou, vertiginosamente, a partir dos anos 1980.

\section{UM CAMPO DE GOVERNO}

Considerando a crescente articulação, no campo do governo, entre as artes (expandidas pelo conceito de diversidade cultural), a economia e as indústrias criativas, Bennett (1998) sugeriu estudar a obra de Foucault de um ponto de vista diferente do que já havia sido adotado pelos britânicos, principalmente pelos representantes dos Estudos Culturais. Ainda na década de 1980, o autor associou-se ao grupo de pesquisa sobre a história do presente, que tinha o objetivo de examinar a composição e a operação de formas modernas de governo em campos diversos, como a economia, a educação, a psicanálise, a ética, a cidadania e a cultura.

Os estudos sobre o liberalismo, que também ganhavam força nos anos 1980, foram fundamentais para as pesquisas de Bennett (1998), que remetia, mais uma vez, a Foucault (2016). Para o último, no regime liberal que emergiu no final do século XVIII, predominava a ideia de que uma sociedade é formada por cidadãos livres, que se articulam para alcançar interesses heterogêneos. No entanto, para que esses cidadãos livres pudessem se integrar à sociedade como indivíduos "normais", eles deveriam seguir certos códigos de conduta e prestar atenção ao próprio comportamento. As chamadas sociedades disciplinares, que compreendiam o mesmo período (do final do século XVIII a meados do século $X X)$, tinham como principal característica a clausura dos corpos em instituições como escolas, hospitais e prisões. Influenciados por essas ideias, pesquisadores como Jeffrey Minson (citado em Bennett, 1988) atribuíram um sentido semelhante aos equipamentos culturais. $E$, de fato, autores influentes do século $X I X$, como o economista William Stanley Jevons, apostavam no caráter utilitarista desses espaços:

a principal razão de ser das bibliotecas públicas e gratuitas, assim como dos museus, das galerias de arte, dos parques, edifícios, relógios, e de muitos outros tipos de obras públicas, é o enorme aumento da utilidade, adquirida, desse modo, pela comunidade por um custo insignificante. Se uma bela pintura estiver dependurada na sala de jantar de uma casa particular, talvez ela seja vista por uns poucos convidados uma ou duas vezes por ano. Sua utilidade real é frequentemente a de contribuir para o orgulho egoísta de seu dono. Se ela estiver exposta na National Gallery, ela será contemplada por centenas de milhares de pessoas, cujos olhares, não é necessário dizer, não tendem a se desviar do quadro. (citado em Bennett, 1998, p. 108)

O "princípio de multiplicação da utilidade", cunhado por Jevons (citado em Bennett, 1998, p. 108), era acompanhado pela ideia de que museus e outras instituições culturais podem ser usados como ferramentas de instrução pública, o que os aproximava 
de programas educacionais, estatísticos e sanitários. Contudo, Bennett (1988) sugere que, embora tenham encerrado as obras de arte entre suas paredes, os museus e outros equipamentos culturais abriram suas portas a grande parte da população. Um exemplo é o South Kensington Museum (Londres, Inglaterra), que foi concebido como um depósito centralizado, a partir do qual objetos artísticos poderiam circular para as províncias, em um esforço para que as influências positivas da cultura se espalhassem pelo território inglês. Analisando esse e outros exemplos, Bennett (1998) percebe uma relação complexa entre estratégias de vigilância e técnicas de espetáculo. Os museus e outros equipamentos culturais, assim como hospitais, escolas e prisões, seriam, de fato, uma resposta ao problema da ordem pública. Mas o empenho em fomentar a cultura envolve algo além da "disciplina e do treinamento dos corpos": a conquista de "corações e de mentes" (Bennett, 1998, p. 76).

Bennett (1998) conclui que o esforço em multiplicar os circuitos da arte é impulsionado por uma lógica governamental: mais do que representar o poder, a arte é vista, ela própria, como uma forma de poder a serviço de um programa cuja finalidade não é exatamente o domínio sobre a população, mas o desenvolvimento de suas capacidades. Novamente é a Foucault que o autor se refere. Para o filósofo francês, uma sociedade é atravessada por campos de saber e de poder. No primeiro, os enunciados que se formam a partir dos discursos de leigos ou especialistas, veiculados em meios de comunicação ou em relatórios oficiais, dispersos nas conversas do dia a dia ou vindos de qualquer outra fonte, produzem "verdades históricas", que servem como referências para uma determinada época. Já o segundo é o domínio das práticas, do "governo das condutas", que orienta os modos de vida e que é permeado por relações de força e de poder. Nesse campo, estão as ações exercidas sobre os indivíduos, seja por eles próprios ou pelas instituições. O entrelaçamento dessas duas dimensões resulta na forma como cada um passa a agir sobre si, governando seus próprios atos e pensamentos (Costa, 2014, pp. 118-119). Nesse sentido, o que as diversas formas de governo liberal propõem é que as pessoas tenham autonomia para conduzir as próprias vidas, sendo guiadas por valores éticos que as inclinem a seguir certos padrões de comportamento. São alguns exemplos o aumento ou a diminuição do consumo, a adoção de hábitos saudáveis e, por que não, a frequência a equipamentos culturais.

O contato com uma obra de arte, no viés estudado por Bennett (2011), é entendido, então, como um exercício que pode fazer com que as pessoas se voltem para si, seja para se comportarem "corretamente" nos espaços culturais (não correr, falar em voz baixa, não comer ou beber, não tocar nos objetos), seja no próprio ato de contemplação. O autor recorre à filosofia para sustentar seu argumento, situando o discurso da estética, especialmente de viés kantiano, no conjunto de tecnologias do governo liberal, que atua por um modo particular de "liberdade guiada". Para o pesquisador inglês, a estética - que emerge com o lluminismo - seria um dentre tantos processos éticos, mais preocupados em induzir os indivíduos a moldarem suas condutas por meio de modos particulares de governo de si do que em prescrever códigos morais. 
O lluminismo é entendido aqui de forma bastante precisa: não como a era da razão, a que o pós-modernismo iria se opor, mas como um modo particular de pensar e agir, em que ainda estamos imersos, marcado pelo constante questionamento do próprio presente e pela incessante busca por verdades (no plural), que se manifestam na ciência ou na sociedade. Essa atitude característica, segundo Osborne (1998), visa, entre outros aspectos, a construção de processos racionais que possam promover a liberdade. Ocorre que "ser livre" também tem um sentido preciso, que Bennett (2011) e Osborne (1998) extraem da obra de Kant: a independência tanto de coerções externas quanto de emoções e sentimentos internos. O ser humano não é livre quando age sem valores morais, mas quando submete suas ações a valores éticos que ele próprio escolheu seguir. A questão torna-se mais complexa quando se pensa nos indivíduos em sociedade.

No artigo "Resposta à pergunta: o que é o lluminismo?", Kant (1784) se dedica ao tema a partir de dois conceitos: os dos usos privado e público da razão. O primeiro refere-se à nossa atividade como "funcionários", "quando somos componentes de uma sociedade ou governo, cujos princípios e objetivos são aqueles do bem coletivo" (Kant, 1784 , p. 35, citado em Bennett, 2011, s. p.). Já o último é aquele que fazemos de nosso entendimento e de nossas faculdades à medida que nos posicionamos como sujeito universal. O desafio iluminista seria justamente fazer um uso público da razão, pensar por si mesmo, sem a tutela de outra pessoa. Mas a proposta do filósofo não é a substituição completa do uso privado pelo uso público da razão. O que o pensador alemão sugere é uma divisão proporcional entre os dois, uma vez que é o uso público da razão - no qual não há relações de tutela nem de autoridade - que regula as esferas nas quais o uso privado é exercido. Ou seja, a liberdade do pensamento leva à conclusão de que obedecer a certos códigos de conduta é fundamental para a integração dos indivíduos em comunidade, para a construção do comum.

Foucault (2013) dedicou as primeiras aulas do curso "O governo de si e dos outros" a esse tema, afirmando que o artigo de Kant foi um dos primeiros textos modernos a tratar do próprio presente e do governo das condutas. Bennett (2011), por sua vez, recorreu a outro filósofo - Deleuze - na tentativa de relacionar essas ideias à multiplicação dos circuitos artísticos. Para os autores, associada ao prazer desinteressado e livre do julgamento conceitual, a estética kantiana abre o caminho para a produção de um espaço de universalidade, no qual os princípios do uso público da razão poderiam ser livremente exercidos. Considerada sob esse viés, a estética operaria como uma tecnologia de si. Sem restrições políticas ou religiosas, a arte seria o campo de uma liberdade potencialmente ilimitada, mas, ao mesmo tempo, inalcançável.

Ainda hoje essas noções são recorrentes. Quando Rancière (citado em Bennett, 2011), por exemplo, propõe o regime estético, ele remonta à obra kantiana, que desconecta a arte das atividades interessadas. O autor refere-se a uma "partilha do sensível", que permite que obras de épocas e lugares distintos dividam o mesmo espaço, recebam novos sentidos e façam parte de novas composições. De acordo com Bennett (2011), até mesmo pesquisadores como Bourdieu estão mais próximos dessas ideias do que 
parecem. Para o sociólogo francês, a arte é, ao mesmo tempo, histórica - porque é resultado de um conjunto particular de circunstâncias sociais e de relações culturais - e trans-histórica - porque é o modo como a obra é condicionada pelas relações sociais que permite que ela se liberte dos limites temporais e os transcenda para alcançar seu valor como fonte de conhecimento. Compreender os processos históricos que levaram ao desenvolvimento do campo artístico permite, por um lado, que os artistas continuem lutando por sua autonomia, ameaçada principalmente por fatores comerciais, e, por outro, que sejam realizados esforços para que mais pessoas possam ter acesso às obras de arte (Bourdieu, 1998).

Se, para Bourdieu (citado em Bennett, 2011), a redistribuição da liberdade pelas classes sociais é alcançada pelo acesso igualitário ao campo cultural, para Rancière (citado em Bennett, 2011), o regime estético da arte permite uma redistribuição do sensível, que assegura o direito ao discurso e enfraquece a distinção entre voz e ruído, em nome da igualdade. O que Bennett (2011) sugere com essas aproximações é que, apesar das diferentes perspectivas, Bourdieu e Rancière, entre tantos outros autores, são produtos de uma tecnologia de governo que busca produzir e distribuir a liberdade. Essas questões não são apenas teóricas. Do empenho em distribuir as obras do South Kensington Museum à preocupação com o multiculturalismo nas escolas públicas britânicas, são os modos particulares de governar as condutas que estão em debate. Bennett não quer dizer que todos os equipamentos culturais foram construídos com o mesmo propósito ou que não existam outras estéticas. O que ele supõe é que, de forma consciente ou não, grande parte do trabalho de gestores, pesquisadores e outros profissionais da área cultural emerge do desejo de abrir esse campo de liberdades, que se torna possível quando os indivíduos se voltam para si e conduzem, de maneira ética, a própria vida.

Longe de ser mera utopia ou certa ideologia ingênua, esses objetivos são coerentes com o pensamento liberal, o que não significa, por outro lado, que sejam corrompidos pelo capitalismo ou que a preocupação de tantos profissionais não seja autêntica. Bennett $(1998,2011)$ considera fundamental o empenho de todos os que buscam expandir o alcance das artes e, justamente por isso, se esforça para mostrar que esse modo específico de compreender as políticas culturais não é algo natural, mas foi construído a partir de enunciados e acontecimentos particulares. Mais do que isso, o autor propõe que, em vez de discutir somente questões ideológicas, sejam analisadas técnicas específicas de governo, que atuam diretamente sobre as condutas individuais. São exemplos, entre outros, ações que podem ampliar o público de um teatro ou estratégias para garantir o acesso a filmes nacionais. Afinal, quando se percebe a "multiplicidade de questões cotidianas no campo da administração cultural" (Bennett, 1998, p. 82), e se reconhece que a cultura é ordinária nesse sentido, fica mais fácil entender, como em qualquer outra área de atividades, que seu futuro depende do modo como questões práticas são formuladas e resolvidas. Dito de outro modo, é a compreensão das forças cotidianas - e das técnicas de governo das condutas - que torna possível a luta por políticas públicas e outras ações de interesse coletivo. 


\section{EMPREENDEDORES DE SI}

Bennett $(1998,2011)$ desenvolve seu trabalho sobre o conceito de governamentalidade, dando ênfase à estética pós-kantiana, mas há outros aspetos da obra de Foucault (2008) que podem contribuir para o estudo das políticas culturais e da dinâmica do campo artístico: o capital humano e o empreendedorismo. Em linhas gerais, Foucault (1998) percebeu uma diferença entre o liberalismo do século XIX e o neoliberalismo que se fortaleceu na segunda metade do século XX: no último período, o trabalho deixou de ser entendido apenas como força produtiva e passou a ser visto como o resultado do investimento em fatores como educação e cultura, que os empregados oferecem em troca de um salário. O que caracteriza o regime neoliberal não é, portanto, o livre mercado, mas a lógica empresarial, a concorrência: quando o trabalho passa a ser um capital, o capital humano, cada trabalhador se transforma em uma pequena unidade-empresa.

O perfil do empreendedor é fundamental nesse ambiente. Nos anos 1940, o economista Joseph Schumpeter (1947) já definia a riqueza em função da ruptura inovadora das rotinas econômicas. Para ele, a invenção vem da potência de criação da sociedade, e o empreendedor é quem se apropria dessa força para inseri-la no processo econômico como uma inovação. Contudo, segundo Foucault (2008), a ousadia do capitalismo e a concorrência permanente não são suficientes para explicar o crescimento econômico. Se as pessoas descobrem novas formas de produtividade, ou fazem invenções tecnológicas, é em função da renda do capital humano ou do "conjunto dos investimentos que foram feitos no próprio homem" (Foucault, 2008, pp. 317-318). Com a expansão das comunicações, essa forma de trabalho deixa de se restringir às fabricas e aos escritórios. Se estamos sempre conectados e em rede, e se não é possível parar de pensar, estamos sempre trabalhando, até mesmo nos momentos de descanso e lazer. Para Foucault, é justamente sobre essa vida, em que se investe constantemente como um capital, que se exerce o poder - a biopolítica ou a política sobre a vida.

Para o pesquisador Peter Pelbart (2013), não é coincidência que a temática em torno da governamentalidade, do liberalismo e do empreendedorismo apareça na obra de Foucault ao mesmo tempo em que o autor investiga o "cuidado de si". O poder é pensado como "ação sobre ação" ou "conduta sobre conduta" e, nesse sentido, tem como condição a própria liberdade dos sujeitos: "o governo concebido como 'estruturação do campo de ação eventual dos outros' supõe um sujeito que lhe corresponda, ou seja correlato, ou lhe resista" (Pelbart, 2013, p. 60). A figura do empreendedor, dotado de capacidade de invenção e seguro de si, é, portanto, perfeitamente coerente com a sociedade neoliberal. É também por meio das relações entre poder e liberdade, entre técnicas de governo e processos de subjetivação, que emergem as questões identitárias e as disputas por sentido, presentes nos mais diversos grupos sociais.

Ora, é tradicionalmente a figura do artista (como construída desde o século XVIII na cultura ocidental) que se volta para si e usa como recurso os próprios processos de subjetivação. Já não se trata, contudo, do gênio kantiano, tampouco da construção de um ambiente de universalidade, embora essas questões não deixem de existir. A preocupação estética resiste e encontra novos caminhos, mas as artes também circulam por outros lugares, dando vozes a distintos grupos sociais: dos pesquisadores que 
investigam linguagens experimentais aos jovens que protestam por meio do hip-hop; dos integrantes das bandas municipais e dos circos itinerantes aos músicos que se dedicam à perfeição formal das peças de concerto; dos produtores mais comerciais aos artistas que transformam em dança, teatro, performance, artes visuais ou literatura as questões de gênero ou os problemas sociais e raciais. A vida desses artistas certamente está investida em seus trabalhos. Por isso, eles reivindicam seu espaço nos circuitos artísticos e culturais, dedicando-se diariamente à execução de seus projetos, filiando-se a partidos políticos ou lutando por políticas públicas. Seus interesses ora se integram, ora entram em conflito nesse terreno em que estão em jogo estética, economia, política e, principalmente, afeto.

Alguns exemplos brasileiros ajudam a dar materialidade a essa questão teórica: nos anos 2000 intensificaram-se movimentos civis que afetaram diretamente os rumos das políticas culturais. Em São Paulo, a articulação de artistas e profissionais da cultura colaborou para a criação e a implementação de diversas ações, como o Programa Municipal de Fomento ao Teatro (Lei $n^{\circ} 13.278 / 2002$ ), o Programa Municipal de Fomento à Dança (Lei $n^{\circ} 14.071 / 2005$ ) e o Programa para a Valorização de Iniciativas Culturais VAl (Lei $n^{\circ} 13.540 / 2003$ ). Mais recentemente, questões sócio-raciais passaram a pautar, com mais intensidade, as reivindicações de uma importante parcela da classe artística. O programa de Fomento à Cultura da Periferia (Lei ${ }^{\circ}{ }_{16.496 / 2016)}$ ilustra alguns dos resultados obtidos. Mas a questão não se restringe ao fomento público, estendendo-se a toda a sociedade. Um exemplo é o aumento do público dos museus em 2019. De acordo com o site $\mathrm{G} 1$, as visitas cresceram $61 \%$ no primeiro semestre do ano: entre os principais motivos estão as exposições que destacam minorias ou grupos antes pouco representados (Matos, 2019). Esses aspectos colocam em evidência o cotidiano dos diversos grupos sociais, seus afetos e percepções, suas angústias e anseios, a vida em si mesma investida na arte. Por outro lado, sua dinâmica pode levar a um ambiente de concorrência, a uma disputa por apoio ou por verbas, o que pode acabar prejudicando o desenvolvimento das políticas para as artes e a cultura.

Mais do que técnicas que visam a produzir e distribuir a liberdade por meio da contemplação estética, é a própria liberdade dos artistas, os modos como conduzem suas vidas e criam suas obras, que chama a atenção na administração cultural - não somente a das políticas de Estado, mas principalmente as que se espalham por iniciativas privadas, organizações não governamentais e outras instituições. Com isso, acaba emergindo também outro aspecto, mais prático, do empreendedorismo. Os artistas devem aprender a escrever projetos, fazer projeções financeiras, entrar em contato com a imprensa ou com departamentos de marketing, ou seja, são obrigados a gerir o próprio trabalho segundo uma dinâmica claramente empresarial. O crescimento das indústrias culturais, os apelos à economia criativa, a lógica financeira que muitas vezes é visível em editais e prêmios voltados ao fomento ao trabalho artístico, as leis de incentivo fiscal, tudo isso, de alguma forma, acaba por reforçar esse modo de pensar e agir. Adotando, então, o método de pesquisa sugerido por Bennett, percebe-se que, atualmente, mais do que a produção da liberdade, o que se governa é a vida do artista como empreendedor de si. 


\section{CONSIDERAÇõES FINAIS}

Em uma sociedade em que predomina certa lógica empresarial e empreendedora, e em que a própria vida é transformada em um objeto de governo, é natural que exista concorrência. Se não se pode falar em um espaço estético universal, mas se multiplicam diversos grupos de interesse, a tendência é que as políticas públicas ou as iniciativas privadas também se fragmentem. É importante e legítimo que as correntes artísticas e sociais se fortaleçam e criem mecanismos de continuidade se, em grande parte das vezes, a cultura não é entendida como prioridade, nem pelo Estado nem pela população em geral. No entanto, vale a pena ouvir o apelo (ainda atual) de Bourdieu (1998) para que os artistas lutem por sua autonomia, principalmente em relação aos interesses comerciais. Também é fundamental a proposta de Bennett $(1998,2011)$ de compreender as técnicas de governo das condutas que incidem sobre os circuitos artísticos.

Quando Bourdieu (1998) ressalta a autonomia, ele não propõe que o campo das artes seja fechado em si, que ignore as questões sociais e culturais ou que seja usado como forma de distinção entre as classes. É justamente porque sua pesquisa denuncia algumas dessas tendências que o autor espera o contrário: que cada vez mais pessoas possam participar dos circuitos artísticos e que tenham liberdade o suficiente para não se deixar determinar pelas forças políticas e econômicas, embora as trocas e relações entre os campos sejam necessárias e inevitáveis. Mas Bourdieu (1998) também chama a atenção para o caráter histórico da arte e mostra que é somente quando se luta por objetivos comuns, como o aumento da verba para a cultura e a construção de políticas públicas abrangentes, que se tem força para propor ações efetivas. Não se trata de lutar por uma arte universal, que provavelmente nunca existiu. Mas de compreender que, quando indivíduos e grupos são capazes de integrar sua potência e seus afetos, também se abre espaço para a multiplicidade de saberes, de expressões artísticas e de modos de vida.

Por outro lado, é preciso lançar um olhar atento ao presente, como ensinou Foucault, para entender as forças que o compõe. Se o conhecimento e a comunicação são hoje fundamentais para a economia e se até mesmo bens de consumo são vendidos como ideologias e imagens, é claro que há interesse pela cultura e pelas atividades criativas. Mas é preciso verificar onde se concentra esse interesse: nas indústrias culturais e nos departamentos de marketing, sem dúvida, mas não somente aí. Como demonstra a atenção voltada à economia criativa, a força reside hoje na capacidade de cada artista empreender e gerar riquezas - e, nesse contexto, a autonomia pode ganhar outro sentido, que leva às ações isoladas e às redes que se fecham em si. Se a potência de invenção existe e, mais do que nunca, está presente na sociedade, como transformá-la em um bem comum? A mensagem de Bennett é clara: envolvendo-se nas questões práticas, conhecendo as propostas culturais dos municípios, dos estados e do país, mapeando as ações e as pessoas envolvidas, debruçando-se sobre leis e editais, mas, acima de tudo, buscando soluções que se estendam à maior parcela possível da população. Assim, as artes e a cultura podem entrar de fato no cotidiano das pessoas, o que, por sua vez, dará força para que os grupos de interesse convivam e afirmem, cada um, sua própria potência. 


\section{REFERÊNCIAS}

Bennett, T. (1988). The exhibitionary complex. New formations, 4, 73-101.

Bennett, T. (1998). Culture. A reformer's science. Londres: Sage.

Bennett, T. (2008). Aesthetics, government, freedom. Key Words: A Journal of cultural materialism, 6, 76-91. Retirado de https://raymondwilliamssociety.files.wordpress.com/2017/10/key-words-6.pdf

Bennett, T. (2011). Guided freedom: aesthetics, tutelage, and the interpretation of art. Tate papers, 15. Retirado de https://www.tate.org.uk/research/publications/tate-papers/15/ guided-freedom-aesthetics-tutelage-and-the-interpretation-of-art

Bocchini, B. (2017, 4 de maio). Ministério estima que cultura é responsável por $4 \%$ do PIB. EBC. Agência Brasil. Retirado de http://agenciabrasil.ebc.com.br/cultura/noticia/2017-04/ ministerio-estima-que-cultura-e-responsavel-por-4-do-pib

Bourdieu, P. (1998). Les règles de l'art. Genèse et structure du champ litteraire. Lonrai: Éditions du Seuil.

Costa, R. (2014). A biopolítica nos estudos sobre pessoas com deficiência. Diálogo (bio)político: sobre alguns desafios da construção da Rede de Cuidados à Saúde da Pessoa com Deficiência do SUS. Brasília: Ministério da Saúde.

Dubuffet, J. (2012). Asfixiante Cultura. In G. Gentil, P. Poirrier \& T. Coelho (Eds.), Cultura e Estado: a política cultural na França, 1955-2005 (pp. 69-71). São Paulo: Iluminuras.

Foucault, M. (2008). Nascimento da biopolítica: curso dado no Collège de France (1978-1979). São Paulo: Martins Fontes.

Foucault, M. (2013). O governo de si e dos outros. São Paulo: Martins Fontes.

Foucault, M. (2016). Microfisica do poder. São Paulo: Paz e Terra.

Furtado, C. (2012). Discurso de posse. In Furtado, C. (Ed.), Ensaios sobre cultura e o Ministério da Cultura. Rio de Janeiro: Contraponto.

Hall, S. (1980). Cultural studies: two paradigms. Media Culture Society, 2 (1), 57-72. https://doi. org/10.1177/016344378000200106

Hesmondhalgh, D. (2013). The Cultural Industries. Londres: Sage.

Lei n० 8.313/1991, de 23 de dezembro, República Federativa do Brasil.

Lei 13.278/2002, de 8 de janeiro, Prefeitura do Município de São Paulo, República Federativa do Brasil.

Lei 13.540/2003, de 24 de março, Prefeitura do Município de São Paulo, República Federativa do Brasil.

Lei 14.071/2005, de 18 de outubro, Prefeitura do Município de São Paulo, República Federativa do Brasil.

Lei $n^{\circ} 16.496 / 2016$, de 20 de julho, Prefeitura do Município de São Paulo, República Federativa do Brasil.

Matos, T. (2019, 12 de agosto). Museus em alta: $1^{\circ}$ semestre de 2019 tem recordes de público pelo Brasil. G1. Retirado de https://g1.globo.com/pop-arte/noticia/2019/08/12/museus-em-alta-10-semestre-de-2019tem-recordes-de-publico-pelo-brasil.ghtml

Osborne, T. (1998). Aspects of Enlightenment. Social theory and the ethics of truth. Oxford: Rowman \& Littlefield. Retirado de https://www.kobo.com/us/en/ebook/aspects-of-enlightenment-2 
Osborne, T. (2003). Against 'creativity': a philistine rant. Economy and society, 32(4), 507-525. https://doi. org/10.1080/0308514032000141684

Pelbart, P. (2013). Foucault versus Agamben? Revista Ecopolítica, 5, 50-64.

Poirrier, P. (2012). Introdução. In G. Gentil, P. Poirrier \& T. Coelho (Eds.), Cultura e Estado: a política cultural na França, 1955-2005 (pp. 17-39). São Paulo: Iluminuras.

Schumpeter, J. (1947). The creative response in economic history. The Journal of Economic History, 7(2), 149-159.

Shiner, L. (2001). The invention of art: a cultural history. Chicago: University of Chicago Press.

Unesco (1970, 24 de agosto a 2 de setembro). Conferencia Intergubernamental sobre los Aspectos Institucionales, Administrativos y Financieros de las Políticas Culturales. Retirado de http://unesdoc. unesco.org

Unesco (2005). Convenção sobre a Proteção e Promoção da Diversidade das Expressões Culturais. Retirado de https://unesdoc.unesco.org/ark:/48223/pfoooo149742

Williams, R. (1967). Culture and Society. Londres: Chatto \& Windus. Retirado de https://www.kobo.com/br/ pt/ebook/culture-and-society

\section{NotA BIOGRÁFICA}

Sharine Machado C. Melo é graduada em Comunicação Social com habilitação em Publicidade e Propaganda pela Escola Superior de Propaganda e Marketing (2005). Mestre (2010) e doutora (2015) em Comunicação e Semiótica na Pontifícia Universidade Católica de São Paulo - PUC-SP, com período de doutorado sanduíche na Universidade de Leeds (Inglaterra). Foi orientada por Rogério da Costa, Kate Oakley e David Hesmondhalgh. Escreveu a tese Artistas e empreendedores: um estudo sobre o trabalho criativo na economia do imaterial. Atualmente trabalha como administradora cultural na Fundação Nacional de Artes (Funarte). Em 2017, desenvolveu, em parceria com Ester Moreira, o site Vozes da Funarte SP (http://sites.funarte.gov.br/vozessp), que apresenta pesquisa histórica e entrevistas sobre políticas culturais brasileiras.

ORCID: https://orcid.org/oooo-0003-3160-1151

Email: sharinemelo@gmail.com

Morada: Funarte, Complexo Cultural Funarte SP - Alameda Nothmann, 1058, Campos Elíseos, São Paulo - SP, Brasil

\section{Submetido: 15.05 .2019}

Aceite: 23.09.2019 